\title{
Ibn Hanbal, un faqîh (jurisconsulte) controversé
}

\section{Lahcen Daaïf}

\section{Résumé}

Depuis la parution du livre intilâf al-fuqahâ' de Tabarî, la question du statut d'Ibn Hanbal a préoccupé plusieurs jurisconsultes et historiographes traditionnistes de toutes obédiences juridiques. Mais si son statut de jurisconsulte est discutable, son rang de traditionniste (muhaddit) est unanimement reconnu ainsi que son affiliation aux meilleurs hommes de Tradition. Comparée au fiqh des trois fondateurs d'écoles sunnites existantes, Abu Hanîfa, Mâlik, aš-Šâfi'î, la conception du droit légal d'Ibn Hanbal s'avère différente. Elle est fondée généralement sur les trois principes suivants : le moindre avis juridique doit plonger ses racines dans le Texte (nass), toute vocation à l'opinion juridique personnelle (ra'y) est exclue et le raisonnement humain ne saurait se substituer au Texte, même quand celui-ci ne propose pas de solution.

\section{Citer ce document / Cite this document :}

Daaïf Lahcen. Ibn Hanbal, un faqîh (jurisconsulte) controversé. In: Horizons Maghrébins - Le droit à la mémoire, $N^{\circ} 51,2004$. Vingt ans de médiation interculturelle euro-méditerranéenne - II - Horizons Maghrébins (1984-2004) pp. 49-61;

doi : https://doi.org/10.3406/horma.2004.2229

https://www.persee.fr/doc/horma_0984-2616_2004_num_51_1_2229

Fichier pdf généré le 05/02/2019 
À certains moments de l'histoire de la pensée musulmane, tel ou tel personnage s'impose comme le chef de file d'une école théologique ou juridique dont, pour diverses raisons, se réclament plusieurs membres en même temps. En règle générale, une telle situation correspond à une reconnaissance, par une élite savante, des compétences de ce personnage dans un domaine donné du savoir religieux. Cependant, lorsqu' on considère le cas d'Ibn Hanbal', on se rend vite compte que cette règle n'est pas tout à fait observée. Elle s'applique sans doute à lui dans le domaine du hadith ${ }^{3}$ mais elle semble ne pas faire l'unanimité en ce qui concerne le domaine du droit légal ${ }^{+}$.

Nous n'allons pas nous étendre ici sur la biographie d'Ibn Hanbal pour expliciter les fondements de cette exception à la règle. Dans cet article, notre propos vise à clarifier quelques points déterminants qui nous semblent à l'origine de la contestation de son statut de jurisconsulte. Pour ce faire nous dirons d'abord qu'à la différence des autres imams fondateurs d'écoles juridiques sunnites, en particulier Abû Ḥanîfa ${ }^{5}$, Mâlik ibn Anas ${ }^{\hbar}$ et aš-Šâfîî̀, Ibn Ḥanbal évite d'émettre la moindre opinion juridique personnelle $\left(r a^{\prime} y\right)$. Il rejette, de surcroît, même s'il est sain, tout raisonnement individuel, au seul profit du sens le plus clair qu'offre le Texte (nass). Par scrupule religieux (wara $)$, Ibn Hanbal ne profère aucune décision juridique qui ne soit expressément fondée sur le Coran et la Tradition du Prophète (Sunna), ou sur l'atarar, c'est-à-dire les choix et les dires des Compagnons et parfois de certains Successeurs de la première génération (tâbi ûn).

Qui dit figh en Islam dit aussi futyâ. Tel qu'il a été pratiqué au moins par les trois autres fondateurs d'écoles sunnites encore existantes, l'exercice de la consultation juridique (futyâ) est un paramètre qui s'impose si l'on tient à faire un parallèle entre eux et Ibn Ḥanbal. Il nous faudrait également prendre en compte les différentes positions exprimées au sujet de son statut de jurisconsulte par les générations de jurisconsultes postérieurs dans les œuvres qui traitent de la divergence des fuqahâ', de la jurisprudence, des biographies de savants illustres de chaque école ainsi que des questions dogmatiques. Mais auparavant penchons-nous sur une position qui constitue le point de départ de la polémique sur le statut d'lbn Hanbal.

\section{L'OUBLI FÂCHEUX DE TABARÎ ${ }^{8}$}

Le premier livre à avoir soulevé indirectement la question du statut d'Ibn Ḥanbal fut écrit par Ibn Garîr aț-Tabarî qui était un éminent

\section{ibn hanbal, un faqih (jurisconsulte) controversé}

\author{
Lahcen Daaif
}


traditionniste. En rédigeant, ihhtilâf al-fuqahâ ${ }^{\prime 9}$ qui traite de la divergence entre les jurisconsultes, Ṭabarî n'y avait pas tenu compte des fatwa-s d'Ibn Hanbal. Il était bien évidemment loin de soupçonner les contestations qu'il allait déclencher. Il s'était attiré ainsi la vindicte des disciples ḥanbalites zélés qui, bien décidés à lui faire regretter cet oubli, s'étaient si bien acharnés contre lui qu'il finit par s'enfermer dans sa maison par peur de représailles" ${ }^{11}$. Les excuses qu'il aurait faites, soidisant en public, n'y changèrent apparemment rien. D'ailleurs, il ne changea rien à sa première version. Si l'on en croit les historiographes, Tabarî était resté fidèle à l'idée qu'il se faisait d'Ibn Hanbal, dans la mesure où l'ouvrage en question avait été retrouvé, après sa mort, enfoui sous terre". Cette situation lui était d'autant plus insupportable qu'il était lui-même un sympathisant et un admirateur d'Ibn Hanbal. Dans son livre Tabarî tient d'abord à mettre en évidence les points de divergences juridiques notables qui ont eu lieu entre les différents docteurs de la Loi, et principalement entre les fondateurs des écoles juridiques sunnites de son époque ${ }^{12}$. Pourquoi avait-il décidé de ne pas faire mention des avis juridiques attribués à Ibn Ḥanbal dont se proclamaient, pourtant, une partie non négligeable de jurisconsultes-traditionnistes à Bag̀dâd?

Ṭabarî semblait avancer pour sa défense la raison suivante: à sa connaissance, il n'existe pas $d^{\prime}$ avis juridiques qui soient rapportés d'Ibn Hanbal, dans les règles de la science de la transmission ('ilm ar-riwâya). Or, le manquement à cette règle signifie que la validité de ces avis n'est pas acquise pour qu'il décide, par conséquent, d'intégrer le nom d'Ibn Ḥanbal dans le domaine de la divergence juridique sunnite (ihtiliâf ou hilâfiyyât $)^{13}$. D'un autre côté, Țabarî avouait ne pas lui reconnaître de disciples proprement jurisconsultes, sur les témoignages desquels il aurait pu fonder un jugement critique personnel. Donc il lui était impossible de reconstituer les chaînes de Garants ${ }^{i t}$ par lesquelles auraient transité les décrets juridiques d'Ibn Ḥanbal, si tant est qu'elles aient existé. Car c'est le seul moyen de transmission qui permet de les diffuser dans les centres d'étude religieux jusqu'à ce qu'ils parviennent à Ṭabarî. À partir de ce point, on comprend que pour Tabarî le processus qui sert à l'acheminement de la matière juridique est celui-là même dont la matière est la Tradition prophétique. Le fait que certains sectateurs d'Ibn Ḥanbal ${ }^{15}$ essayent de forcer d'autres voies en faisant l'impasse sur ce processus, ne fait que rendre à ses yeux nulle et non avenue toute prétention au statut de faqih pour Ibn Ḥanbal.

Comme n'importe quel autre titre en sciences religieuses, celui de jurisconsulte (faqîh) ne s'attribue pas seulement aux savants ayant des connaissances en sciences de la Tradition comme le pensent les contradicteurs de Tabarî. Ce titre renvoie au couronnement d'une longue formation pratique qui implique en premier lieu une participation confirmée aux consultations juridiques. Déjà à Kûfa, au premier siècle de l'hégire, la

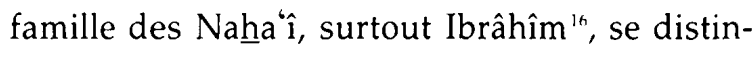
guait des traditionnistes par ses compétences juridiques. À examiner de près le parcours de la plupart des jurisconsultes reconnus comme tels, on voit que le statut de fagih ne se passait jamais de l'émission des décrets juridiques. Encore faut-il qu'une telle tâche ne corresponde pas à une usurpation de titre, dans la mesure où il n'est pas question que l'on se proclame soi-même jurisconsulte. Être faqih c'est l'aboutissement d'une formation continue qui repose sur l'affiliation traditionnelle de disciple à maître. À l'issue de chaque formation les maîtres décident ou non d'accorder à leurs disciples le droit d'être consulté et de donner leurs avis juridiques. C'est justement à cette affiliation que fait allusion Ṭabarî dans son argumentaire. Force est d'admettre que c'est dans l'exercice constant et régulier des diverses fonctions liées au futyâ que se forge la vocation indé- 
niable du jurisconsulte, et qu'à la longue se façonne cet esprit distinctif qui caractérise les grands jurisconsultes.

\section{LE FIQH DU POINT DE VUE DES TROIS FONDATEURS}

Examinons à présent quelques témoignages relatifs à ce thème. Nous allons nous limiter uniquement aux trois fondateurs éponymes mentionnés plus haut, en respectant l'ordre chronologique de l'apparition de leurs écoles.

\section{Abû Hanîfa}

Même s'il a été cité par le Ḥanbalite Ibn Qayyim al-Grawziyya ${ }^{17}$ dans le cadre de la polémique sur la validité du raisonnement individuel en droit légal qui caractérise les relations entre Ḥanafites et Ḥanbalites, le propos qui suit nous informe qu'Abû Hanîfa avait conscience de son rang de jurisconsulte et de l'exercice qu'il implique: "Notre savoir-ci, disait Abû Hanîfa, procède du raisonnement personnel. Et c'est ce que nous avons pu faire de mieux. Aussi, quiconque est dans la capacité de nous proposer une [solution] meilleure, nous l'accepterons volontiers de lui ${ }^{1 x}$.» C'est quelque part un défi lancé à ses détracteurs, quoique exprimé avec humilité. On trouve ailleurs des témoignages où sa conscience du fiqh était précocement ressentie. Entre les différentes branches du savoir dispensées à son époque: la science des lectures du Coran, la grammaire, la poésie, la Tradition, la théologie dogmatique et le droit légal, Abû Ḥanîfa avait sciemment opté pour les fonctions consécutives à la dernière spécialité qu'est le droit légal'". C'est parce que, poursuivit-il, on l'avait préalablement informé qu'en choisissant la voie $\mathrm{du}$ droit légal «on viendra te consulter, puis tu donneras des fatwas. On ira même jusqli'à te solliciter pour la magistrature sans trop tenir compte de ton jeune âge?"."
D’où sa décision ferme lorsqu'il affirma: « $E t$ j'ai décidé dès lors qu'il n'existe pas de savoir plus utile que celui-ci, et je m'y suis, de suite, consacrée1. .» C'est à ces fonctions-là que nous devons le choix du figh par Abû Ḥanîfa. En vertu de leur utilité immédiate, ces fonctions constituent une garantie certaine contre les critiques publiques, y compris celles des traditionnistes qui vont s'intensifier plus tard ${ }^{22}$. Néanmoins, ce choix est dû aussi aux avantages qui découlent de ces fonctions, outre l'estime et les honneurs dont pourraient jouir celui dont le statut de faqîh est reconnu.

Du point de vue juridique, l'affiliation d'Abû Ḥanîfa en tant que disciple est assurée par plusieurs jurisconsultes 'irâqiens qui étaient ses maîtres. Celui qui est le plus souvent cité d'entre eux comme son principal maître en droit légal est le magistrat et jurisconsulte Ḥammad ibn Abî Sulaymân ${ }^{23}$. À travers lui, il rejoint directement la grande école de 'Irâq, à savoir celle de Kûfa.

\section{Mâlik ibn Anas}

Lorsque l'on vient au cas de l'imam Mâlik ibn Anas, on voit qu'il avait également cette nette conscience de son rôle de jurisconsulte qui s'adjoint à son statut d'homme de hadith (muhaddit ). Pour exercer la consultation juridique, précisons qu'il ne s'était point proposé pour donner des fatwas de son propre chef. L'aval de plusieurs éminents savants lui avait été dûment accordé pour pouvoir s'attribuer l'exercice de ce privilège, d'où son affiliation au niveau juridique. "Je ne me suis permis, déclara-t-il, de décréter des fatwas qu'après avoir consulté plus doctes que moi et m'être assuré qu'ils me jugeaient bien à la kauteur de cette tâche $e^{24}$.» $C^{\prime}$ est à ce titre que l'on s'était publiquement permis de raviver, à son avantage, des rivalités avec d'autres jurisconsultes de Médine ${ }^{25}$. Sans omettre les grandes divergences qui l'opposaient, sur le plan juridique, à Abû Ḥanîfa en particulier et plus généralement aux jurisconsultes des écoles 'irâqiennes qui avaient adopté certains procédés de 
raisonnement juridiques qu'il jugeait hétérodoxes. Son œuvre maîtresse al-Muwatta', est essentiellement un ouvrage de droit légal ${ }^{26}$. Mâlik avait pris soin d'en disposer les chapitres suivant l'ordonnancement qu'impliquent les matières juridiques traitées, de telle sorte que le hadith y côtoie et l'atar et la pratique vivante des gens de Médine ${ }^{27}$. Même si le Muwatța' se veut un ensemble de traditions homogène, Mâlik y introduit par-ci par-là son opinion personnelle ${ }^{28}$.

En outre, les séances que présidait Mâlik étaient consacrées au figh. Les hadiths y circulaient, à la rigueur, en tant que preuves scripturaires. Ils n'y étaient pas une matière d'enseignement en soi que l'on pourrait considérer strictement indépendante de son activité principale qu'était le droit. C'était une pratique courante que de donner le pas au figh dans des séances réservées à la consultation juridique. Héritée des anciens jurisconsultes de Médine ${ }^{24}$, cette pratique, qui faisait probablement partie des coutumes de transmission du savoir, tendait à distinguer l'enseignement de la Tradition de celui du figh.

Du fait de sa prééminence dans les centres d'étude 'irâqiens, le fiqh avait suscité un intérêt particulier pour qu'aussitôt des séances lui soient consacrées. Si l'on veut bien ajouter foi à certaines informations dont on dispose à ce sujet ${ }^{30}$, on apprendra que Mâlik réservait une séance (mağlis) à part à la transmission des hadiths. D'une certaine manière, la Tradition était reléguée au second plan, parce que la fatwa pourrait tout aussi bien résulter d'un effort de réflexion juridique (iğithâd) où l'opinion individuelle prendrait le pas sur le Texte. Dans ces séances de figh, l'effort personnel n'était pas seulement agréé, mais il fondait parfois des solutions juridiques. Par l'intermédiaire de cette forme singulière de Sunna que constitue pour Mâlik le principe de 'amal ahl alMadina, il arrive que l'opinion personnelle l'emporte sur un hadith explicite ${ }^{31}$.

\section{Ařšsafi}

Il n'en va pas autrement pour l'imam Aš-Šâfi'î qui laissait clairement entendre qu'il avait acquis son statut de faqîh depuis déjà sa tendre enfance ${ }^{32}$. Muslim az-Zinğ ${ }^{33}$, l'un de ses premiers maitres en droit légal l'avait solennellement investi de cette mission. Il l'autorisa devant l'assistance à prendre place en sa présence pour émettre des décrets juridiques (iftâ') alors qu'il n'avait même pas atteint l'âge de vingt ans ${ }^{34}$. Mais cette affiliation ne se limite pas seulement à ce maître. À la Mecque, il fréquentait certes az-Zinğ $\hat{\imath}^{35}$, mais de temps en temps aussi Ibn 'Uyayna ${ }^{36}$. À Médine, auprès de l'imam Mâlik la formation d'aš-Šâfiî̀ était principalement dirigée vers le droit légal. Après son départ de Médine, il partait ensuite en 'Irâq où il fréquenta les grands disciples d'Abû Hanîfa avant de prendre pour destination l'Égypte. C'était à Bagdâd où il côtoya le jurisconsulte et traditionniste, disciple d'Abû Ḥanîfa et d'Abû Yûsuf alQâḍ̂î̉, le mawlâ Muḥammad ibn al-Ḥasan.

L'étude du Muwatta', qui avait fait l'objet d'une mémorisation complète de la part d'ašŠâfi î ${ }^{3}{ }^{38}$, était considérée comme une étape nécessaire dans la formation d'un faqîh. Pour preuve, il est intéressant de savoir que même aš-Šaybânî, son rival ḥanafite, s'était évertué à transcrire le Muwatṭa ${ }^{\prime 34}$. Pourtant à en croire le jurisconsulte et célèbre réformateur hạnbalite, Taqiyyadîn Aḥmad Ibn Taymiyya (661-1263/728-1328), c'est à celui-ci que l'on doit les premiers traités de divergences juridiques (hilâff). Il les avait rédigés à l'adresse de ses contradicteurs qui étaient majoritairement médinois ${ }^{40}$. Ayant été informé des traités d'ašŠaybânî, aš-Šâfiî̂ s'était attelé à son tour à en faire la critique. Après avoir minutieusement étudié ces traités, il donna raison aux positions juridiques des savants de Médine, et ce faisant appuya les thèses des traditionnistes" ${ }^{4}$. Cet esprit caractéristique des jurisconsultes se manifeste également chez aš-Šâfiîi dans les célèbres controverses publiques (munâzarât) qui l'opposaient à aš- 
Šaybânî. Celles-ci n'auraient pas eu lieu s'il n'y avait pas eu un fonds de fatwas sur lequel les deux hommes étaient en désaccord. La critique du principe d'istiḥsân ḥanafite ${ }^{\dagger 2}$ par aš-Šâfi'î, ainsi que celle dirigée contre son maître Mâlik dont il juge une somme de positions juridiques analogues au jugement préférentiel témoignent de ses qualités de théoricien du droit ${ }^{+3}$.

À travers ces trois jurisconsultes fondateurs nous avons relevé qu'il y a une conscience commune relativement à la pratique juridique, une distinction nette entre deux filières figh et hadît où ce dernier passe au second plan, et une affiliation juridique du même ordre que celle en cours dont les sciences du hadith. Reste à savoir si ces conditions sont réunies lorsqu'il est question du futyâ et de la fatwa chez Ibn Hanbal? Pourrait-on envisager le futyâ comme une activité principale et autonome dans sa vie quotidienne?

\section{IBN HִANBAL, TRADITIONNISTE OU JURISCONSULTE?}

Efforçons-nous en premier de faire un peu de lumière sur les indices qui nous mettraient sur la voie concernant l'affiliation juridique d'Ibn Hanbal. Cette affiliation nous semble être la mesure qui convient pour justifier une légitimité en droit légal, laquelle recouvre la procédure suivie en matière de hadith lorsqu'elle consacre comme hâfi i ${ }^{+4}$ un savant traditionniste.

Il n'est pas tout à fait exact de considérer comme affiliation les rapports qu'entretenait Ibn Ḥanbal avec aš-Šâfiî̀. En effet, la nature de ces rapports ne permet pas de les ranger sous la rubrique des relations qui lient ordinairement un disciple à son maître. Certes, le sujet est connu pour être très controversé d'autant plus que ces rapports sont très difficiles à déterminer. Bien qu'un nombre $\mathrm{d}^{\prime}$ informations nous aient permis de relever tantôt la Mecque, tantôt Bagdâd ou les deux à la fois comme lieux de la rencontre des deux hommes, en réalité nous savons peu de chose quant à la durée de cette ou de ces rencontres. Pour ce qui est de leur(s) date(s) et de leur(s) nombre(s), il n'est pas aisé d'y apporter une réponse satisfaisante sans nécessairement être de l'opinion des uns contre celle des autres. Si l'on regarde, par exemple, du côté des Šâfi'ites, on remarque que la version la plus modérée veut qu'aš-Šâfiî̀ soit bien son maître en droit légal et en principes du droit (uŝul al-fiqh), mais pendant quelques courts moments seulement. Selon cette version šâti ite Ibn Hanbal n'avait appris d'aš-Šâfiî̀ que les enseignements dispensés dans ses cours publiques les plus fréquentés ${ }^{45}$.

Toutefois, en dépit de leur admiration pour Ibn Hanbal, certains jurisconsultes šâfi'ites ont tenté de faire de lui un simple disciple d'aš-sâfi î. Le grand hâfiz et jurisconsulte šâfi ite Aḥmad ibn al-Husayn Abû Bakr al-Bayhaqî (384/994458/1066), en est l'illustration. Dans la monographie laudative qu'il a écrite sur Ibn Hanbal, Manâqib al-imâm A ḥmad, il cherche à prouver qu'il fut un disciple d'aš-Šafi î $i^{\text {th }}$. De leur côté les Hạanbalites avancent un tout autre avis au sujet de cette relation. Ibn Taymiyya, par exemple, admet volontiers la rencontre des deux hommes. Mais il ne tient compte que d'une seule rencontre, celle qui eut lieu lors de la deuxième visite d'aš-Šâfíî̀ à Bag̉dâd avant son départ définitif en Égypte ${ }^{\dagger 7}$. Par conséquent, il rejette l'autre rencontre pendant laquelle Ibn Hanbal aurait été indécis entre le cercle d'enseignement d'Ibn 'Uyayna et celui d'ašŠâfi'î, et qui est supposée avoir eu lieu à la Mecque $^{+8}$. Du point de vue d'Ibn Taymiyya, la rencontre de Bag̀dâd ne s'était pas tenue dans un cadre d'enseignement traditionnel qui d'ordinaire reliait un disciple à son maître. Elle s'apparente plutôt à un moment de rencontre habituel où deux grands savants d'une stature identique échangent leurs points de vue ${ }^{+4}$.

Le rejet de la première rencontre par Ibn Taymiyya serait dû à l'image que les chroniques ren- 
voient d'Ibn Hanbal: celle d'un jeune homme partagé entre son admiration et son émerveillement devant l'intelligence aiguë d'aš-Šâfiî̀, et son estime pour Ibn 'Uyayna qu'il considère comme une haute autorité dans les chaînes de Garants supérieures ('uluzww al-isnâd). Ce rejet serait dû aussi à la déclaration d'Ibn Ḥanbal lorsqu'il s'exclama: "[..] il ne m'a pas été donné de voir plus doué dans la connaissance de la religion de Dieu que ce jeune qurayšite ${ }^{\text {so }}$ ». Le fait qu'Ibn Hanbal nomme intelligence ('aql) cette faculté distinctive d'aš-Šâfîî, et décide de tirer au plus vite le meilleur parti de cette rencontre qui ne risquerait plus de se reproduire, équivaut pour $\mathrm{Ibn}$ Taymiyya à reconnaître à aš-Šâfíî des qualités juridiques dont Ibn Ḥanbal serait dépourvu ${ }^{51}$.

Mise à part son historicité controversée, la rencontre rejetée par Ibn Taymiyya montre qu'en choisissant le cercle d'enseignement d'aš-Šâfi î, Ibn Hanbal a décelé une spécificité d'ordre intellectuel propre aux hommes de droit. Il en a fait état en tant qu'apanage des fuqahâ', mettant du coup en évidence l'absence de cet esprit parmi les hommes rompus à l'étude de la Tradition. L'hypothèse $d$ 'une adéquation entre traditionnisme et droit légal ne tient plus.

Nous voyons de ce qui précède se dégager deux méthodes d'argumentation antagoniques: d'une part le raisonnement individuel que fonde l'intelligence, de l'autre la citation qui repose sur le Texte. Ces deux procédés renvoient à deux qualités propres chacune à un domaine du savoir religieux. D'ailleurs, en hommage à aš-Šâfiî̀, on prête à Ibn Ḥanbal ce propos "le droit légal était lun domainel clos pour les non-initiés, jusqu'à ce que Dieu

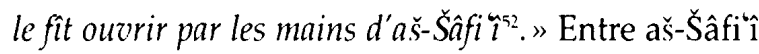
et Ibn 'Uyayna, tous deux jurisconsultes et traditionnistes, Ibn Hanbal ne se prononce pas, à ce moment-là, sur les qualités juridiques d'Ibn 'Uyayna, mais il reconnaît à aš-Šâfi'î d'authentiques qualités d'un faqîh de haut rang. On comprend qu'il tient à différencier les deux hommes par la supériorité juridique d'aš-Šâfiî̀.
À condition de la resituer dans un contexte propre que nous avons auparavant tenté de circonscrire, la consultation juridique nous entraîne dans ses fonctions et ses enjeux à nous interroger sur la différence entre Ibn Hanbal et les imams fondateurs de rites juridiques. Nous constatons d'emblée que son titre de jurisconsulte souffre de l'absence d'affiliation, dans la mesure où ses liens juridiques avec aš-Šâfiłî̀ ne font pas l'unanimité. Ce n'était pas non plus sa notoriété de jurisconsulte-mufti qui était à l'origine du différend théologique qui l'opposait au Pouvoir 'abbâside. Autrement dit, l'emprisonnement d'Ibn Hanbal, au terme duquel a eu lieu la grande Épreuve $(m i h ̣ n a)^{i 3}$, est étrangère à ce cadre de futyâ, et partant n'inclut, ni ne concerne son titre de jurisconsulte.

Par contre la notoriété d'Ibn Hianbal en tant que traditionniste à travers l'empire 'abbâside, était due aux multiples voyages entrepris, dans la quête du hadith, vers la plupart des milieux religieux et des centres d'enseignement du hadith. Cette notoriété s'était renforcée grâce à son rang supérieur de critique et d'homme de haute estime en matière d'isnâd. Sa valeur en tant que Garant de hadith faisait de lui une autorité de premier ordre: les collecteurs et rapporteurs de hadiths (ruwât) ne cesseront d'affluer de partout pour recueillir ses transmissions. Ces trois titres, collecteur, garant de hadiths et critique des hadiths et de leurs transmetteurs, ne font pas objet de contestation. C'est pourquoi ils forment les fondations d'un statut idoine pour que le pouvoir politique, dans l'espoir de faire admettre sa thèse du Coran créé, porte un intérêt particulier à Ibn Hanbal. Il s'agit là d'un statut de traditionniste (mu hạddiț) qui s'est imposé progressivement grâce à une élaboration dissemblable de celle qui détermine le statut de faqîh.

S'il en est ainsi de ses compétences de traditionniste, en droit légal on a rarement fait cas de ses compétences. Cela dit, quelques anecdotes his- 
toriographiques le mentionnent en train de prendre part au figh, puisqu'il nous a été décrit, lors d'un de ses déplacements successifs, participant activement au futyâ. Nous devons garder à l'esprit cependant que cet exercice avait lieu dans un cadre beaucoup plus public. Voici que l'on nous signale sa présence à la Mecque, comme enseignant et consultant juridique. Il y était visiblement appelé à satisfaire et la curiosité des collecteurs de hadiths et celle des pèlerins qui l'interrogeaient sur les préceptes et les interdits relatifs au pèlerinage.

Nous avons quelques informations éparses concernant le moment et le lieu de cette scène. C'était vers la fin du deuxième siècle de l'hégire, en l'an 198/813. Mais puisque cette date se trouve être l'année même de la mort d'Ibn 'Uyayna "4, maître d'Ibn Hanbal, on peut dire que l'information renvoie à leur rapport de maître à disciple, et semble faire allusion à la succession de celui-ci à celui-là. Elle laisse entendre, en effet, qu'lbn Hanbal était en matière de futyâ le digne disciple à même d'occuper la place de son maître à la Mecque. Pour ce qui est du lieu où cette scène se serait déroulée, il s'agit de la grande mosquée d'al-Hayf. Ibn Ḥanbal était alors âgé de trentequatre ans ${ }^{35}$.

Il apparaît paradoxalement que c'est Ibn 'Uyayna, son maître en hadith, et non pas aš-Šâfiî̀ qui a exercé une influence considérable sur Ibn Hanbal. L'ascendance d'Ibn 'Uyayna sur lui passait aussi par l'ensemble des valeurs morales régulant l'esprit de sa conduite lors de l'exercice de la consultation juridique $(f u t y \hat{a})$. Quand bien même la Mecque semblerait avoir été le lieu de prédilection où Ibn Hanbal avait vraisemblablement tenu un rôle d'homme de fatwa, le lien fort particulier qui le rattachait aux principes de valeurs de l'école bașrienne, à travers son maître Ibn 'Uyayna, n'en serait que plus amplement confirmé. La vision ascétique bașrienne qui enrobe la pensée juridique d'Ibn Ḥanbal, n'emprunte pas seulement la voie classique de l'enseignement de son maître Ibn 'Uyayna qui est originaire de Bașra. Cette vision est consécutive aux nombreuses visites et longs séjours qu'il avait effectués dans celle ville ${ }^{\text {in. }}$.

Ses compétences juridiques font l'objet de soins et d'éloges des chroniqueurs partisans et ont suscité quasi systématiquement des commentaires laudatifs. Ibn Hanbal y a droit à beaucoup d'estime et d'égards de la part de ses condisciples, parfois même de la part d'un maître jurisconsulte. Ainsi du témoignage que l'on attribue à Abû 'Âșim aḍ-Ḍahhâk égale en figh et en hadit qui, suite à une série de questions auxquelles aurait répondu Ibn Ḥanbal brillamment, l'aurait déclaré un véritable $f a q i h^{\text {*x }}$.

Avec Ibn Hanbal, le statut de mufti s'enracine dans le champ exclusif du hadith et de l'atar, tant ce domaine constitue l'origine de sa matière première. Le récit portant sur sa discussion à propos du prêt à usage (al-'âriya) avec son condisciple Yazîd ibn Hârûn ${ }^{\text {jy }}$ le montre bien. Ce dernier aurait fini par admettre son erreur en donnant raison à Ibn Ḥanbal, et l'aurait même remercié de l'avoir éclairé par un hadith qu'il lui aurait enseigné et que Yazîd ignorait ${ }^{(x)}$. Mais ce tête-à-tête ne saurait s'apparenter à une controverse (munâzara) à caractère juridique, telle qu'aš-šâfíî aimait tant non pas seulement à les susciter, mais aussi à les tenir en public. Bref, pour Ibn Ḥanbal le noyau de toute fatwa est logé au sein du corps scripturaire de la Tradition et ne peut être le résultat de débats de réflexion humaine. La preuve en est que lorsqu'une question fait l'objet de deux propositions différentes étayées par deux nasss-s explicites, Ibn Ḥanbal se conforme alors à une règle de principe en vertu de laquelle mieux vaut s'abstenir de donner son avis juridique que de devoir prendre parti pour l'une des deux solutions juridiques scripturaires. Nous citerons une autre anecdote pour bien souligner ce principe. On rapporte qu'une personne était peinée d'avoir sciemment négligé la 
quête du hadith pendant qu'elle assistait à l'enseignement des récitations coraniques dispensé à la mosquée, mais quand elle se consacrait au hadith elle était peinée aussi d'avoir abandonné la noble science des Lectures coraniques ${ }^{\text {t1 }}$. Elle vint alors auprès d'Ibn Ḥanbal solliciter son avis pour savoir lequel du hadith ou du Coran constitue un enseignement prioritaire. Ibn Ḥanbal répondit par un choix personnel, que l'on qualifierait plutôt de non-choix ${ }^{62}:$ "Je te conseille l'un et l'autre let de répéter] l'un et l'autre».

Dans ce cas précis, c'est bien sûr la mise en suspens de toute intervention humaine qui est requise. Quand le nass vient à manquer, la consultation juridique et même théologique portant sur des questions doctrinales très sensibles se passe de la mesure humaine pour s'accommoder de l'état de suspension qu'implique le mutisme du Texte. C'est ainsi que la fatwa peut s'intégrer dans le corps juridique scripturaire qui se veut une unité homogène. Le Texte (nașs) délimite ainsi un champ de savoir qui enclos toutes les activités relatives à la profession de futyâ. En d'autres termes, la fatwa est reliée d'autant plus étroitement à son noyau dur qu'est le naș qu'elle est appelée à s'y dissoudre.

Autrefois, réservées à la consultation juridique et destinées à un large public, les séances (mağâlis) avaient une fonction distincte des séances habituelles d'enseignement du hadith. Ce n'était pas le cas avec Ibn Hanbal, même lorsqu'il s'agit des moments où il aurait donné un avis juridique. Les rassemblements autour d'un mufti se faisaient à des heures précises afin que les gens puissent venir le consulter. La différence s'accentue quand on sait que c'est le rassemblement des disciples autour d'Ibn Hanbal qui a prévalu comme cadre pour la plupart de ses fatwas. Donc, le privilège de l'enseignement du hadith à ses disciples participait au raffermissement de son statut d'émetteur de décisions juridiques. Mais eu égard à son dévouement pour la Tradition, le peu d'intérêt porté au figh à travers les quelques avis juridiques à peine formulés ${ }^{63}$ nous fait voir dans quel cadre de connaissance religieuse Ibn Hanbal concevait le futyâ.

Suivant les témoignages des traditionnistes, y compris ceux qui se proclamaient de lui, Ibn Ḥanbal était considéré le plus prolixe ${ }^{6 t} \mathrm{~d}^{\prime}$ entre tous les imams traditionnistes qui ont rédigé des recueils de hadiths. Mais dans son Musnad ${ }^{65}$, où il se borne à regrouper les hadiths selon leurs chaines de transmetteurs, des critiques mettent le doigt sur quelques hadiths faibles ( $d q \hat{\imath} f \hat{f})$. Certains d'entre eux osent même parler de hadiths apocryphes (mawodûu $a)^{\text {twt. }}$. En effet, en se référant à son ouvrage, on constate que les hadiths y sont regroupés pêle-mêle, les faibles y côtoient les sains. L'objet qui y importait n'était évidemment pas de composer un recueil de hadiths où les chapitres seraient disposés en fonction des thèmes déterminés par le $f i g h^{67}$. Avec beaucoup de largesse dans sa manière d'appliquer les règles relatives au contrôle des chaînes de Garants, Ibn Hanbal s'était employé assidûment à mettre sur pied l'un des recueils de hadiths les plus touffus qui soient. Le fait de l'avoir composé plutôt sous forme de musnad que de sunan ${ }^{6 *}$, témoigne qu'il n'avait pas l'intention d'en faire un ouvrage juridique $^{\text {"in. }}$.

En raison de nombreux maîtres qu'il eut et grâce à la quantité considérable de traditions qu'il recueillit durant de longues pérégrinations, Ibn Hanbal fut reconnu aussi bien par des biographes jurisconsultes que traditionnistes comme un imam très abondant en hadith et un éminent critique averti ${ }^{7 \prime}$. Sa notoriété en ce domaine n'est plus à démontrer. Aux jugements de l'écrasante majorité des critiques des Garants de hadiths (naqd arriğâl $)^{71}$, il fut l'imam par excellence, le Garant qualifié d'homme digne de foi (tiqa) et porté au rang de preuve ( $h u$ ğğa $a)$ en matière religieuse.

Mais si l'écriture du hadith est un fait indiscutable, force est de rappeler que de son vivant, Ibn 
Ḥanbal n'a pas rédigé d'ouvrage de droit légal. Bien plus, il est historiquement établi qu'il n'a pas composé de son propre chef le moindre recueil de fatwas à l'adresse de ses disciples - lesquels ne formaient pas autour de lui un cercle d'étude du figh. À cet égard, on ne peut se dispenser de signaler qu'il a déconseillé formellement à ses disciples de mettre par écrit ses avis juridiques, ses choix personnels ou même ses moindres suggestions ${ }^{72}$ relatives aux fondements du droit (usûul) ou aux prescriptions pratiques (fur $\hat{u})$.

Par principe de piété scrupuleuse (wara), Ibn Hanbal tenait beaucoup à ce que l'on ne transcrivît pas non plus les points de vue juridiques des autres imams. Et il n'en exclut aucun, pas même aš-Šâfîî et sa Risâla ${ }^{-3}$ qu'il semblait apprécier pourtant dans sa jeunesse. Il répétait souvent que seule la tradition du Prophète, pour la bonne raison qu'elle constitue la vraie source du droit en islam après le Coran, mérite de faire l'objet de l'écriture afin qu'elle soit préservée ${ }^{i t}$. De là le jugement qu'il porta sur les œuvres juridiques de son contemporain Abû Tawr al-Kalbî (170/786240/854) $)^{\pi /}$ qu'il aurait appelées œuvres innovatrices $(k u t u b u \text { bid } a)^{i}$. Son interdiction formelle de tirer le moindre avis juridique du Kitâb al-Hiyal d'Abû Hanîfa, au risque d'être taxé d'impiété va dans ce sens ${ }^{\pi}$.

Sous de telles recommandations, c'est la systématisation de la citation qui est visée, comme procédé solidaire de cet esprit de désengagement dont a toujours témoigné Ibn Hanbal à chaque fois qu'il a été question de consultation juridique. La citation avec lui s'est substituée aux divers procédés de raisonnement propres à chaque région. Du coup, c'est la validité de sa conception du figh qui devient sujette à caution. À moins de considérer son figh comme une catégorie à classer à part, les consultations juridiques attribuées à Ibn Hanbal ne suffiraient pas à inscrire son nom dans le registre commun des fuqahâ'. C'est pourquoi un bon nombre de jurisconsultes et de traditionnistes suivront l'exemple de Tabarî en réitérant son exclusion de la liste des jurisconsultes. Ainsi, en traitant des divergences juridiques, les doctes jurisconsultes les plus remarquables semblent ne s'en tenir généralement qu'aux opinions juridiques des trois fondateurs des écoles sunnites ${ }^{78}$, évitant de prendre en considération celles du quatrième. À leurs yeux, Ibn Hanbal paraît ne pas avoir légué une pensée strictement juridique au même titre que celle des autres fondateurs.

Lahcen Daaif est docteur en Islamologie. Il poursuit actuellement des recherches en droit légal classique, et travaille à la publication de sa thèse sur Ibn Hanbal.

\section{Notes}

* Je remercie Mr le professeur A. Elamrani-Jamal (CNRS, Villejuif) d'aroir bien voulu lire cet article et pour ses précieuses suggestions dont j'ai pris note pour le réécrire.

1. Cet article est tiré de plusieurs chapitres remaniés de notre thèse de Doctorat, soutenue sous la direction de A. ElamraniJamal, Ibn Hanbal entre traditionnisme et droit légal. Étude sur le statut d'un juriste à l'ombre de l'ascèse, Paris III-Sorbonne Nouvelle, 2004.

2. Abû 'Abdallâh Aḥ. ibn Muḥ. ibn Hilâl ibn Asad aḍ-Duhlî ašŚaybânî al-Bagda dí naquit à Bag̣dâd en 164/780 et y mourut en 12 rabî̀ I $241 / 30$ juillet 855 ). Il y a de nombreuses biographies laudatives sur Ibn Hanbal, dont la plus ancienne est celle de son fils Abû al-Faḍl Sâlị̣ ibn Ạ̣. ibn Ḥanbal, Sîrat al-imâm A hmm. ibn Hanbal., éd. F. 'Abdalmun im Ah., Alexandrie, Mu'assasat Šabâb al-Gâmi'a, 1984, voir aussi la plus célèbre de toutes, celle d'lbn al-Gaw'zî, Manâqib al-imâm Ah. ibn Hanbal,

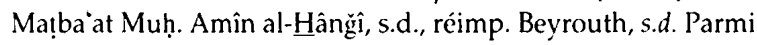
les sources primaires qui contiennent une notice biographique d'Ibn Ḥanbal, nous préférons renvoyer à: Ibn Abî Ḥâtim, Kitâb al-Garth u'a t-ta'dill, I-IX, 2 éd. étáb. par 'Abdarrahmân ibn Yahyâ al-Mu'allimî al-Yamânî, Haydarâbâd, 1973 [1" éd. 1941-

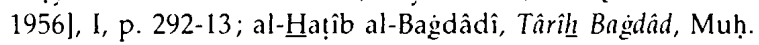
Sa î̀d al-'Irâqî, le Caire, Maktabat al-Hânăĝ̀, 1931/1349, IV, p. 412-23, n² 2317; Abû Nu'aym al-Ișahânî, Hillyat al-aưliyấ'., IX, p. 161-233, n 445; adي-Dahabî, Siyar a lâm an-mubalâ', éd. Š̉ayb al-Arnâ'ût ct alii, 1-XXV, Beyrouth, Mu'assasat ar-Risâla, 19811988/1401-1408, XI, p. 177-358, n 78. Et parmi les sources secondaires, nous conseillons l'article de H. Laoust, "Ahmad b. Hanbal", in Encyclopédie de l'Islam, deuxième édition, I-X, Leyden, E. J. Brill, 1960-2002 [E.I.], I, p. 280-86; id., Les schismes dans l'Islam, Paris, Payot, 1965, p. 115-118; "A Ạmad ibn Hanbal", in The Newe Encyclopaedia Britannica, Micropeadia to reference, I-XII, Chicago, 1985"; F. Sezgin, Geschichte des Arabischen Schrifttums, Leiden, E. J. Brill, 1967 [GAS], I, p. 502-09.

3. L'ensemble des textes où se trouvent consignés les propos, les actes ou l'absence d'actes attribués au Prophète de l'islam.

4. Au lieu de jurisprudence musulmane, nous estimons cette traduction plus juste pour rendre le mot filh (droit musulman). 5. An-Xu'mân ibn Iâbit ibn Zûtâ ibn Mâh al-Kûfî, client affranchi (maallâ) de la tribu de Banû Taym ibn Ia laba, né en 80/699 et mort en 150/767; jurisconsulte et fondateur de l'école juridique hanafite. Cf. Ibn Qutayba, al-Ma ârif, éd. Saroite Okacha 
(sic), Le Caire, Mațba`at Dâr al-Kutub, 1960, p. 495; Ishâaq anNadîm (Ibn an-Nadîm), K. al-Fihrist, éd. Rị̣â Tağaddud, 3 éd., Beyrouth, Dâr al-Masîra, 1988, p. 254-61; al-Bagdâdî, Târîh.., op. cit., XIII, p. 323-424, n 7297; Muh. Abû Zahra, Abû Hanifa, hayâtuhu wa 'aşruhu wa., Le Caire, Dâr al-Fikr al-'arabî, 1977'; GAS, I, p. 409-19.

6. Abû 'Abdallâh ibn Mâlik ibn Abî 'Âmir ibn 'Amr al-Assbahîi, mort à Médine en 179/795. Traditionniste et jurisconsulte à Médine, fondateur de l'école Mâlikite. Cf. Ibn Sa'd, at-Tabaqât al-kubrâ, al-qism al-mutamim li-tâbi ${ }_{i}$ ahl al-Madîna wa man ba 'dahum, éd. Zivâd Muh. Mansûr, Médine, Dâr lḥyâ' at-turât al-islâmî, 1983/1403, p. 433-444, n 372; Ibn Qutayba, Ma ârif, p. 498-99; Ibn Abî H̦âtim, K. al-Garḥ., I, p. 11-32; al-Isffahânî, Hilya., VI, p. 316-55, nº 386; 'Abdalganiyy ad-Daqr, al-Imâm Mâlik ibn Anas., Damas, Dâr al-Qalam, coll. "A'lâm almusliminn", n 23, 1990/14102; GAS, I, p. 457-64; J. Schacht, "Mâlik b. Anas", in $E I$ ', VI, p. 247-250.

7. Abû 'Abdallâh Muh. ibn Idrîs ibn al-'Abbâs aš-Šâfiî̀, né en Palestine à Ġazza en 150/766 et mort à Fustât en Égypte, en 204/820. Il fut disciple de Mâlik avant de fonder son école juridique. Cf. Fihrist, p. 263-64; al-Bag̀dâdî, Târîh., II, p. 56-73, $n^{\circ} 454$; al-Isfahânî, Hilya., IX, p. 63-161, n 415; M. Abû Zahra,

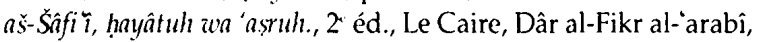
s.d.; GAS, I, p. 484-90; E. Chaumont, "al-Shâfiî̀ ", in EF, IX, p. 187-191.

8. Abû Gałfar Muḥ. ibn Garîr ibn Yazîd, naquit à Rayy en 224$5 / 839$ et mourut à Bagdâd en $310 / 923$. Il fut non seulement jurisconsulte, traditionniste, exégète, et fin connaisseur des différentes Lectures du Coran, mais aussi philologue, lexicographe, grammairien, poète, et historiographe. Il fonda lui aussi une école juridique, la Garîriyya. Cf. Ibn an-Nadîm, Fihrist, p. 291-92; al-Bagdâdî, Târîh., II, p. 126-69, nº 589; alQifṭ̂, Inbâhu r-ruwât 'alâ antâhi n-nuhât, I-IV, éd. Muh. Abû AlFạ̣l Ibrâhîm, Le Caire, Dâr al-Fikr al-'arabî, 1986/14061, III, p. 89-90, n 616; Yâqût al-Hamawî, dans Mu'ğam al-Udabâ', I-XX, éd. Margoliouth, revue par Aḥ. Farîd ar-Rifầî, Le Caire, Dâr alMa'mûn, 1355/1936-1357/1938; GAS, I, p. 323-28 ; C. E. Bosworth, "Ṭabarî", in $E F$, X, p. 11-16.

9. Selon Yâqût al-Ḥamawî, dans Mu 'gam al-Udabâ', XVIII, p. 71, cet ouvrage avait à l'origine le titre suivant: Ihtilikf 'ulumû' alamsî̀r fi a hkîm šarâ'i" nl-islâm. Rappelons que les éditions que l'on en a aujourd'hui sont incomplètes et fragmentaires. Les plus usitées actuellement sont: Ihlitilâf al-fugahâ', éd. F. Kern, 1902, réimp. Beyrouth, Dâr al-Kutub al-ilmiyya, s.d., et Das Konstantinopler Fragment de's Kitâb lhtilâf al-fuqahâ', éd. J. Schacht, Leiden, E. J. Brill, 1933.

10. Cf. ad-Dahabî, Siyar., op. cit., XIV, p. 274.

11. Cf. Yâqût, $M u$ ğam., XVIII, p. 59.

12. D'après Yâqût encore, $c f$. ibidem., Tabarî a passé en revue plusieurs avis juridiques de Mâlik, 'Abdarrahmân ibn 'Amr alAwzầî (88/707-157/773), Sufyân aț-Tawrî $(95,96$ ou 97/710161/778), Šâfi î, Abû Hanîfa, ainsi que les avis des deux grands disciples de ce dernier, Abû Yûsuf Yả qûb al-Qâdî (182/798), et Muh. ibn al-Ḥasan aš-Šaybânî (132/749-189/804). Mais il a retiré de son livre (asqạalu min kitâbih), les avis émis par certains jurisconsultes théologiens ( $a h l$ an-nazar), dont les positions dogmatiques ne sont pas conformes à celles de l'orthodoxie sunnite.

13. La notion d'al-l'tidâd bi-l-hilâf, qui consiste à prendre en compte les avis divergents des jurisconsultes, est souvent mise en avant comme un procédé qui vise, dans une perspective comparative, à rétablir un consensus entre les différentes opi- nions juridiques. Ne pas tenir compte de l'avis d'un faqîh alors qu'il ne fait preuve d'aucune entorse au sunnisme, cela sousentend qu'il n'en est pas un. À titre d'exemple, voir la divergence des spécialistes en hillâf sur les avis juridiques de Dâwûd ibn 'Ali az-Zâhirî (200 ou 202-270/815 ou 817-873), Ibn Katîr, alBidâya wa n-nihâya, I-XIV, éd. Aḥ. Abû Mulhịim et Fu'âd asSayyid, Beyrouth, Dâr al-Kutub al-ilmiyya, 1985/1405, XI, p. 59; ad-Dahabî, Siyar., op. cit., XIII, p. 92.

14. Cf. Yâqût, Mu ğam., XVIII, p. 58 ; voir la traduction française du récit de cette histoire selon Yâqût, par $\mathrm{Cl}$. Gilliot, in Exégèse, langue et théologie en Islam. L'exégèse coranique de Tabarî, Paris, J. Vrin, 1990, p. 252-53.

15. Il s'agit principalement d'un groupe de Ḥanbalites dirigés par le jurisconsulte et polémiste 'Abdallâh ibn Sulaymân ibn al-Ašat Abû Bakr ibn Abî Dâwûd as-Siğistânî (230/844$316 / 928$ ) qui s'était converti au hanbalisme vers la fin de sa vie et devint l'un des plus fervents sectateurs d'Ibn Hanbal. Son père est l'éminente figure du traditionnisme Abû Dâwûd asSiğistânî, auteur de l'un des six recueils de hadiths (al-kutub assitta).

16. Abú 'Imrân ibn Yazîd ibn Qays al-Yamânî mort 96/714-15 à Kûfa. Naha'î transmit des hadiths en petite quantité. Il était le chef de file de l'école juridique de Kûfa. Cf. Tabaqât., VI, p. 270-84; Ma ârif, p. 463; Hilya., IV, p. 219-40, $\mathrm{n}^{\circ} 273$ (erreur dans la table des matières à la page 392 : au lieu de p. 219 , il est marqué p. 217); Siyar., IV, p. 520-29, n 213; Bidâya., IX, p. 146. Deux autres membres de la famille de Nahâî passent pour être de grands fuqahâ' tout en étant souvent cités dans les chaînes de Garants les plus estimées (asânîd 'âliya): 'Alqama ibn Qays (m. 62/682), grand jurisconsulte de Kûfa, qui avait la particularité de donner des fatwas à des Compagnons qui venaient le consulter, et Aswad ibn Yazîd anNahâî $(75 / 694)$.

17. Abû 'Abdallâh Šamsaddîn Muḥ. ibn Abî Bakr ibn Ayyûb ibn Sa'd, naquit en 691/1292 et mourut en 751/1350 à Damas. Traditionniste, exégète, théologien, grammairien, jurisconsulte et théoricien du droit hanbalite, il fut élève d'Ibn Taymiyya en ussull et en hadit et était considéré comme l'un de ses disciples les plus dévoués. Cf. Ibn Rağab, Kitâb ad- $\underline{D} a y l$ 'alâ tabagât alṭnanbila, I-II, éd., Muḷ. Hâmid al-Fiqî, Le Caire, Maṭba’at asSunna al-muhammadiyya, 1952/1372-1953/1372, II, p. 447-451, $n^{\circ}$ 551; Ibn Hağar, ad-Durar al-kâmina fi ahbâr al-mi'ati ț-tâmina, Haydarâbâd, Dâ'irat al-Ma ârif, 1350, réimp. Bayrouth, Dâr alGîl, s.d., III, p. 4ij0-03; Geschichte der Arabischen Literatur, I-II, Leyde, Brill, 1943-1944 [GAL], II, p. 105-06 et Supp., II, p. 12628

18. Ibn Qayyim, I Tâm al-muzuqqi în 'an rabbi l-âlamîn, I-IV, éd. Ṭaha 'Abdarra'ûf Sa'd, Beyrouth, Dâr al-Ǧil, s.d., I, p. 75.

19. Târîh., XIII, p. 331-32; Ibn al-Gawzî, al-Muntazam fî târîh alumam woa l-mulûk, I-XVIII, éd. Muḥ. 'Abdalqâdir 'Atâa \& Muș̣afâ 'Abdalqâdir 'Aṭ̂â, Beyrouth, Dâr al-Kutub al-ilmiyya, 1992/1412, VIII, p. 129-30.

20. Cf. al-Bagddâdì, Târîh., op. cit., XIII, p. 332: “l..J qultu : fa-laysa

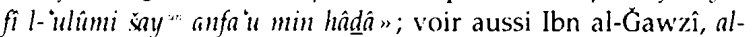
Muntazam., III, p. 130.

21. al-Bagddâdî, Târîh., ibid., Ibn al-Ğawzî, al-Muntazamm., ibid. 22. Ces propos sont attribués à Abû Hanîfa dans sa jeunesse, donc approximativement vers la fin du premier siècle de l'hégire ou, au plus tard, au début du deuxième siècle de l'hégire. Il semble qu'à cette époque le traditionnisme n'était pas encore une force d'opposition organisée contre le ra'y et le figh de l'école irâqienne. 
23. Il fut un client affranchi du fils d'un compagnon du Prophète, Ibrâhîm ibn Abî Mûsâ al-Aš arî. Il mourut en 120/737, cf. Ibn Qutayba, Ma ârif., op. cit., p. 625, Ibn an-Nadîm, Fihrist, p. 256.

24. Cf. al-Ișfahânî, Hilya., op. cit., VI, p. 316.

25. Cf. al-Humaydî, Gadwat al-muqtabas fî dikr zulât al-Andalus, Le Caire, ad-Dâr al-Misriyya li-t-ta'lîf wa t-tarğama, 1966 , p. $158, n^{\circ} 290$, notice d'Abû Ishâq Ibrahîm ibn Naşr asSaraqustî. Ce qui révèle un tout autre aspect des rivalités entre Mâlik et les autres jurisconsultes de Médine au sujet de la fatwa. Les gouverneurs pourraient ainsi intervenir pour des raisons politiques ou personnelles, afin de favoriser l'un au détriment de l'autre, tel que fut le cas ici en faveur de Mâlik et le jurisconsulte traditionniste 'Abdal'azîz ibn 'Abdallâh ibn Salama al-Mâğisûn (m. 164/780, sur lui, ad-Dahabî, Siyar., VII, p. 309-12, n 102; Šadarât., I, p. 259) et contre Abû al-Hâriț Muh. ibn 'Abdarraḥmân ibn al-Mugîira ibn Abî Díb en l'an 148/765. Ibn al-Murtadâ, dans Kitâb Tabaqât al-Mu tazila, [Die Klassen der Mu taziliten], éd. Susanna Diwald-Wilzer, Beyrouth/Wiesbaden, Bibliotheca Islamica, XXI, 1961/1380, F. \$2, évoque une rivalité plus accusée avec Ibrâhîm ibn Yahyyâ al-Madanî, un autre jurisconsulte médinois de tendance mu tazilite. Voir une autre version où le jurisconsulte Ibn Abî Di'b (80/699-159/775) est reconnu mufti au même titre que Mâlik à Médine, cf. Abû Isḥâq aš-Šîâzîi, Tabaqât al-fuqahâ', éd. Iḥsân 'Ảbâs, 2" éd., Beyrouth, Dâr ar-Râ'id al-arabî, 1981/1401, p. 6J. Voir aussi sur cet appel public en faveur de Mâlik, al-Qâdị 'Iyâd, Tartîb almadârik ua taqrîb al-masâlik li-ma rifat a lâm madhab Mâlik, I-V, éd. Aḥ. Bakîr Mahmûd, Beyrouth/Tripoli (Lybie), 1967/1387, I, p. 87.

26. M. Abdel-Magid Turki "Le Muwat!a' de Mâlik, ouvrage de figh entre le hadith et le ra'y", in Studia Islamica, LXXXVI, 1997, p. $5-35$, p. 34 .

27. A. Turki, ibidem.; Noël. J. Coulson, Histoire du droit islamique, traduit par Dominique Anvar, Paris, PUF, 1995 (1 $1{ }^{\cdots}$ éd. Edimburgh, 1964), p. 46

28. A. Turki, ibid., p. 19-21.

29. Cf. Ibn Qayyim, I lâm., op. cit., III, "Risâlat al-Layt ilâ Mâlik», p. 84 : " hattâ iḍ̣arraka mâ karihta min dâlika ilâ firâqi mağlisih." Il s'agit des séances de figh de son maître Abû 'Utmân Rabî̀a arRa'y (136/753), qui fut anciennement disciple d'Abû Hanifa et auquel justement Sufyân aț-Tawrî fit le même reproche qu'à Abû Ḥanîfa, en le qualifiant de chef de file du ráy à Médine, cf. al-Bagdâdî, TârîhL., XIII, p. 395.

30. Abû al-Qâsim Ibn 'Asâkir, Târiḥ madînat Dimašq., I-LXXX (I-VI index), éd., Muhibbaddîn Abû Sa î̀ 'Umar ibn Ġarâma al-'Amrawî, Beyrouth, Dâr al-Fikr, 1995/1416-2001/1421, LI, p. 286: Mâlik informait Ŝâfî̀, par servante interposée, qu'il y a une séance spécialement réservée à l'enseignement du hadith.

31. Cf. Yasin, Dutton, The Origins of Islamic Law. The Qur'ân, the Muwatua' and Madinan 'Amal, Richmond, Curson Press, 1999 p. 4. Mâlik voit ce principe de "Madinan 'amal as authoritative", cf. ibid., p. 36.

32. Al-Bagdâdî, Târîh. II, p. 64

33. Abû Hâlid ibn Hâlid ibn Sa îd, client de la tribu des Banû Mahzzum, originaire de Syrie, mourut à la Mecque en 180/796. Il fut un très grand jurisconsulte et muftì attitré à la Mecque, mais sa fiabilité, en tant que Garant de hadiths, fut mise en cause. Les critiques s'accordaient unanimement à dire qu'il était souvent sujet à l'erreur, et ils le faisaient, par conséquent, figurer sur la liste des Garants faibles ( $d u^{\prime}$ 'afá'). Ibn Ḥanbal éga- lement le taxait de du \%. Cf. sur lui, Ibn Sa`d, Tabaqât., V, p. 499; ad-Dahabî, Siyar., VIII, p. 176-78, n' 22.

34. L'âge varie entre quatorze et vingt ans, cf. al-Bagdâdî, Târîh., II, p. 64; Ibn 'Asâkir Târîh madînat Dimaš̀., op. cit., LI, p. 304, p. 306-08.

35. Ibn Manzûr, Muhtasàr târîh Dimašg l-Ibn 'Asâkir, I-XXIX, Beyrouth, Dâr al-Fikr, 1984/1404-1988/1408, XXI, p. 368.

36. Ibidem. Ibn 'Uyayna: Ibn Abî 'Imrân ibn Muḥ. ibn Maymûn al-Hilàli Abú Muh. al-Kûfí (198/813) fut client (mawlâ) de Muh. ibn Muzâhim. Grand traditionniste et jurisconsulte dont les critiques de hadith étaient satisfaits de ses transmissions, et le considéraient comme rapporteur digne de foi. Voir sur lui Ibn Qutayba, Ma ârif, p. 506-07; Ibn Abî Ḥâtim, al-Ğarh., op. cit., I, p. 32-54; Ibn an-Nadîm, Fihrist, p. 282; Ibn Sa'd, Tabaqât., V, 497 98; Isffahânî, Hilya., VII, p. 270-318, nº 390.

37. Ya qûb ibn Ibrâhîm ibn Hạabîb mourut à Bag̣dâd en 182/798. Il fut le premier jurisconsulte à avoir été nommé aux fonctions du juge des juges (qâự̂l al-qudật) par le Calife Hârûn ar-Rašîd. Cf. sur lui, Ibn Qutayba, Ma ârif, p. 499; al-Bagdâdî, Târîh., XIV, p. 242-62, n 7558; ad-Dahabî, Siyar., VIII, p. 535-39, nº 141.

38. Ibn 'Asâkir Târị̂ madînat Dimasọ́., LI, p. 286, p. 292, p. 295.

39. Il s'agit de Abû 'Abdallâh Muḥ. ibn al-Ḥasan ibn Zufar (ou Farqad) aš-Šaybânî (132/749-189/8j4), qui eut sur aš-Šâfîî une grande influence en matière de figh (cf. sur lui al-Bagdâdî, Târih., II, p. 172-82, $\mathrm{n}^{\circ}$ 593), auteur de l'une des recensions du Muwattea' les plus appréciées: al-Muzwatța' bi-riwâyat Muh. ibn al-Ḥasan aš-Šaybânî, éd. 'Abdalwahhâb 'Abdallaṭîf, Beyrouth, Dâr al-Qalam, s.d.

40. Cf. Ibn Taymiyya, Minhâğ as-Sunna an-nabawiyya fî naqd kalâm aš-š̀ia al-qadariyya, I-IX, éd. Muḥ. Rašâd Sâlim, ar-Riyâd, Mu'assasat Qurtuba, 1986/1406, VII, p. 533.

41. Ibid., VII, p. 532; voir aussi lbn 'Asâkir Târîh madînat Dimašq., LI, p. 283-84, p. 288-89, p. 291, p. 297; Ibn Manzû̂r, Muhtasar., XXI, p. 364.

42. Il a consacré un livre à la réfutation de la notion d'istihsân, cf. Kitâb al-Umm, I-VIII (en I-IV tomes + t. V, Mulhtasar alMuzanî), établi par Muḥ. Zuhrî an-Nağğâr, Beyrouth, Dâr alMa rifa, s.d., "Kitâb ibṭâl al-istiḥsân», VII, p. 293-304, p. 301.

43. Cf. Sâtîî, K. al-Umm, op. cit., VII, p. 191-96: «K. Intilâf Mâlik wa š-Sâfîî" où sont relatés les points essentiels sur lesquels Šâfi'î est en désaccord avec Mâlik.

44. Est hâfit dans les sciences du hadith le traditionniste qui mémorise une grande quantité de hadiths avec leurs chaines de Garants, en sachant la valeur de chaque hadith grâce à une bonne connaissance de tous les rapporteurs qui l'ont transmis. Du moins, précisent d'autres savants, la quantité des noms des Garants que le hâfiz mémorise doit être plus grande que celle des noms des Garants qu'il ignore. Pour plus de précision voir, Galâladdîn as-Suyûtị̂, Tadrîb ar-râwî̀ fí šarh taquî̉ an-Nawâûî (sic), I-II, éd. Ah. 'Umar Hâšim, Beyrouth, Dâr al-Kitâb al'arabî, 1985/1405, I, p. 24 sqq.

45. Cf. c'est ce qu'lbn Katîr soutient, dans al-Bidâya., op. cit., X, p. 341 .

46. Cf. H. Laoust, Le's schismes., op. cit., p. 180. Quant à Tâğaddîn as Subkî, dans Tabaqât aš-Š̂fi ìyya al-kubrâ, éd. 'Abdalfattâh Muḥ. al-Hulw' et Maḥmûd Muḥ. a! -Ṭannâhî, Le Caire, Maṭba at 'Îsâ al-Bâbî al-Halabî, 1964-1976, réimp. Beyrouth, Dâr Ihyầ' atturât al-'arabî, s.d., II, p. 29, il affirme, comme information allant de soi et qui plus est étayée par des dires attribués à lbn Hanbal lui-même, que celui-ci fut l'ẻlève d'aš-Šâfiî̀ en figh.

47. Selon Ibn Taymiyya, les deux visites d'aś-Sâfiî̀ à Bagdâd eurent lieu à presque dix années d'intervalle. Il pense que la 
première s'est déroulée approximativement vers l'an 180/79, en précisant que c'était avant la mort de Muh. ibn al-Hasan (m. $189 / 804$ ) et après celle du Qâḍ̂ Abû Yûsuf (m. 182/798) et pense que la seconde a eu lieu après l'an 190/805, cf. id., Minhâğ., op. cit., VII, p. 533. Pourtant, Ibn Katîr, lui, compte trois visites successives, dont la deuxième correspondrait à sa rencontre avec Ibn Ḥanbal, laquelle est supposée avoir eu lieu en 195/810, cf. Bidâya., op. cit., X, p. 252.

18. Voir entre autres Isfahânî, Hilya., IX, p. 98-99; Ibn Manzûr, Muhtasar., XXI, p. 379-80.

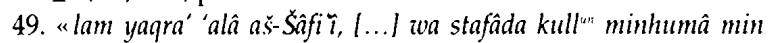
sâhibih. " Et Ibn Taymiyya d'ajouter que c'est exactement la même chose qui s'était produite auparavant entre le Hanafite Muḥ. ibn al-Ḥasan aš-Šaybânî et aš-Šâfi'î, ce qui n'implique pas un rapport de maître à disciple, cf. idem., Minhâğ as-Sunna., op. cit., VII, p. 533.

50. Cf. Issfahânî, Hilya., IX, p. 99; Ibn Manzûur, Mulıttașar., XXI, p. 380.

51. Ibidem.

52. Cf. Ibn Manzûr, Muhtatasar., XXI, p. 383.

53. Sur l'épreuve d'Ibn Ḥanbal (mihna), et les différentes références à consulter à son sujet, $c f$. notre thèse, Ibn Hanbal entre traditionnisme., op. cit., p. 303-323.

54. Cf. Ișfahânî, Hilya., IX, p. 164; Ibn 'Asâkir, Dimašq., V, p. 296; Ibn al-Gawzî, Manâqib., p. 187, p. 188; ad-Dahabî, Siyar., XI, p. 191.

55. Cf. Ișfahânî, ibid.; Ibn 'Asâkir, ibid.; Ibn al-Ğawzî, ibid., adDahabî, ibid. Dans Manâqib.. p. 188, une note de l'éditeur souligne que cette deuxième version qui stipule qu'lbn 'Uyayna était encore vivant au moment où Ibn Hanbal donnait des fat-

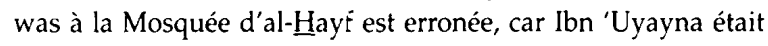
mort en cette année bien avant la saison du pèlerinage. Pour plus de détails concernant ce sujet nous renvoyons à notre thèse, Ibn Hanbal entre traditionnisme., op. cit., p. 205-06, note 176, p. 296, note 497.

56. Cf. Șâliḥ ibn Aḥ, Sîrat al-Imâm., op. cit., p. 32; Ibn al-Ğawzî, Manâqib., p. 22, p. 27, p. 50-51 et passim.

57. Il s'agit du jurisconsulte traditionniste Abû 'Âșim an-Nabîl aḍ-Ḍaḥhâk ibn Mahllad al-Başrî aš-Šaybânî (m. 211 ou 212/826 ou 827). Sur lui, cf. Ibn Sa'd, Țabagât., VII, p. 295; Ibn Qutayba, Ma ârif, p. 520.

58. Voir à titre d'exemple le témoignage d'Abû 'Âșim aḍḌaḥ̂âkk, dans Ișfahânî, Hịlya., IX, p. 168-69 ; Ibn 'Asâkir, Dimašq., V, p. 297.

59. Abû Hâlid Yazîd ibn Hârûn ibn Zâdî al-Wâsiṭ̂ (118/736206/820) fut un éminent commentateur du Coran, mais aussi un jurisconsuite et traditionniste de tendance ascétique, considéré digne de foi. D'ailleurs, Ibn Ḥanbal transmit de lui certaines traditions. Sur lui voir Ibn an-Nadîm, Fihrist, p. 284; GAS, I, p. 40.

60. Cf. Muğiraddîn al-'Ulavmî, al-Manhağ al-ahmad fî tarâğim aşhâb al-imâm A ḥmad, I-V, éd. 'Abdalqâdir al-Arnâ'û! \& alii, Beyrouth, Dâr Șâdir, 1997, I, p. 155.

61. Ibidem.

62. Cf. Ibn Abî Ya lâ, Țabagât al-hanâbila., I, p. 23: "I..I fa-qâla: bidâ wa bi-dâ [...l, bi-dâ wa bi-d̂dà: "Il répondit : lje te conseille] ceci et cela [...], ceci et cela."

63. Excepté certains cas où il serait difficile de fournir des raisons explicatives, en général, quand il se prêtait à la futyâ, il le faisait avec discrétion. Parfois il empruntait des expressions allusives (voir par exemple l'une des masâ'il rapportées par son disciple Abû Bakr al-Ațram Aḥ. ibn Muḥ. ibn Hâni' ạt-Tấ'î (m.
261/869) dans Abû al-Farağ Ibn Rağab, Kitâb ad- Dayl 'alâ țabaqât al-hanâbila, I-II, éd., Muḥ. Ḥâmid al-Fiqî, Le Caire, Mạ̣ba at as-Sunna al-muhammadiyya, 1952/1372-1953/1372, I, p. 248), parfois il mimait avec ses mains les gestes rituels à accomplir, répondant par là à une question d'ordre cultuelle, $c f$. par exemple, Ibn Abî Ya'lâ, Tabaqât al-ḥanâbila, I-II, étab. Muh. Ḥâmid al-Fiqî, Le Caire, Maṭba'at as-Sunna al-muḥammadiyya, 1952/1371, réimp., Beyrouth, Dâr al-Ma'rifa, I, p. 36-37; et sur l'une des masâ'il d'al-Atram, cf. ibid., p. 67.

64. Nous citerons entre autres Abû Țâlib al-Makkî, Qût al-qulûb fi mu "âmalat al-maḥbûb wa was tarị̂ al-murîd ilâ maqâm at-tawhîd, I-II, Le Caire, al-Maṭba'a al-Maymaniyya, 1310/1892, réimp.

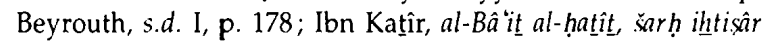
'ulûm al-hadît, 2" éd., établie par Aḥ. Mụ̣. Sâkir, Beyrouth, Dâr al-Kutub al-ilmiyya, 1370/1951, qui précise à la p. 32 que: "aucun autre musnad ne l'équizaut en termes de quantité".

65. Dans le Musnad d'Ibn Hanbal, les hadiths se comptent par milliers, environ quarante mille hadiths selon Ibn an-Nadim, cf. Fihrist, p. 285. Ibn al-Ǵawzî, dans Șayd al-ĥâtir, Beyrouth, Dâr al-Kutub al-ilmiyya, éd. 'Abdalqâdir Aḥ. 'Aḷâ, 1992/1412, p. $244, \S 175$, spécifie que dans ce total que compte le Musnad il y a au moins dix mille hadiths répétés.

66. Cf. Ibn Katîr, a!-Bầit al-hatît, p. 31 : «fa-inna fihi a hâa dịta dạ îfa bal wa mawựî $a$ ": "il contient des hadiths faibles voire même apocryphes". 67. Cf. Ibn Ḥanbal, Musnad., I-VI, éd. Muh. 'A. 'Abdaššâfî, Beyrouth, Dâr al-Kutub al-'ilmiyya, 1993/1413'.

68. Dans le recueil de musnad les hadiths sont regroupés selon les noms des Compagnons du prophète qui les ont transmis, dans celui de sunan ils sont répartis en fonction des thèmes juridiques traités.

69. En principe, eu égard à l'ordre selon lequel sont disposés ses chapitres, le K. al-Musnad, dans le cadre des sciences de la Tradition, n'a point été composé pour être un livre de référence en matière de preuves légales. Attendu que ce rôle est plutôt conféré aux œuvres des Sihâh et des Sunan. Dans leur argumentation, les différents masânîd (plur. de musnad), tel celui d'Ibn Râhawayh, d'ad-Dârimî, d'al-Ṭayâlîsî, ou d'Abû Bakr alBazzâr etc., nous précise Galâladdîn as-Suyûtị̂, n'atteignent pas au niveau des premiers, cf. id., Tadrib ar-râavî., op. cit., I, p. 138.

70. Voir ses avis critiques en ce sens dans son Kitâb al- "llal wa ma'rifat ar-riğâl bi-riwâyat 'Abdallâh ibn Aḥ. ibn Hanbal, I-IV (index IV), éd. Wasiyyallâh 'Abbâs, Beyrouth, al-Maktab alIslâmî, 1988-1408.

71. Citons à titre indicatif, al-Bagdâdî, Târîh., IX, p. 415; Ibn 'Asâkir, Dimašq., V, p. 260, p. 282 et passim; Ibn Manẓûr, Muhtasar., III, p. 241 ; Ibn Katîir, Bidâya., X, p. 350.

72. Cf. Ibn Abî Yàlâ, Tabaqất al-hanâbila, op. cit., I, p. 39: «Ne transcris rien, car je n'aime pas transcrire mon opinion (lâ taktub šn' 'n fa-innî akrahu an aktuba ra'yî)"».

73. Ibid., I, p. 38, p. 57, et passim.

74. Ibid., I, p. 329 , cf. aussi Ibn al-Ğawzî, Manâqib., op. cit., p. 192.

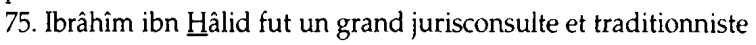
digne de foi. Après avoir été un fervent adepte du $r a^{\prime} y$, il se rallia aux thèses d'aš-Sâfîî, dont il devint par la suite un disciple très dévoué. Al-Kalbi finira par donner naissance à sa propre école juridique, al-Kalbiyya, qui prévaudra particulièrement en Arménie et en Azerbaidjan. Cf. sur lui, Ibn Abî Hâtim, al-Ğarḥ., op. cit., II, p. 97-98, $\mathrm{n}^{\circ} 266$; Ibn an-Nadîm, Fihrist, p. 265; alBagdâdî, Târîh., VI, p. 65-69, n 3100; ad-Dahabî, Siyar., XII, p. 72-76, n० 19; J. Schacht, "Abû Thawr", in EF, I, p. 159. 76. Ibn Abî Yàlâ, Ṭabugâut al-hanâbila, I, p. 329; Ibn al-Gaw'zî, ibidem. 
77. Ibn Abî Yàlà, Tabaqât al-hanâbila, I, p. 218

78. Allusion au livre du Mâlikite andalou Ibn 'Abdalbarr Abû 'Umar Yûsuf ibn 'Abdallâh an-Namarî al-Qurțubî (368/978463/1071), al-Intiqâ' fi faḍl al-a'imma at-talâta al-fuqahâ' : Mâlik ibn Anas, Muḥ. ibn Idrîs aš-Šâfi ì, Abû Hanîfa an-Nu mân, Beyrouth, Dâr al-Bașâ'ir al-islâmiyya, 1997.

\section{Résumé}

Depuis la parution du livre ihtilâf al-fuqahâ' de Tabarî, la question du statut d'Ibn Hanbal a préoccupé plusieurs jurisconsultes et historiographes traditionnistes de toutes obédiences juridiques. Mais si son statut de jurisconsulte est discutable, son rang de traditionniste (muhaddiț) est unanimement reconnu ainsi que son affiliation aux meilleurs hommes de Tradition. Comparée au figh des trois fondateurs d'écoles sunnites existantes,
Abû Hanîfa, Mâlik, aš-Šafi'î, la conception du droit légal d'Ibn Hanbal s'avère différente. Elle est fondée généralement sur les trois principes suivants: le moindre avis juridique doit plonger ses racines dans le Texte (nass), toute vocation à l'opinion juridique personnelle $\left(r a^{\prime} y\right)$ est exclue et le raisonnement humain ne saurait se substituer au Texte, même quand celui-ci ne propose pas de solution.

\section{Mots-clés}

Ibn Ḥanbal, faqih (jurisconsulte), figh (droit légal), traditionnisme, hadît (Tradition), Sunna (tradition orale), ra'y (opinion juridique personnelle), Tabarî, Abû Ḥanîfa, Mâlik ibn Anas, aš-Šâfi'î 